\title{
Role of Active Control in Increasing Base Pressure at Sonic Mach Number
}

\author{
Fharukh Ahmed G. M., Sher Afghan Khan
}

\begin{abstract}
Use of micro jets as an active control mechanism to control the base pressure in suddenly expanded flow from the C-D nozzle exhausted to the duct is investigated in this article. Experimental analysis is carried out at sonic Mach number and different nozzle pressure ratios. The enlarged diameter used in this investigation is $16 \mathrm{~mm}, 22.5 \mathrm{~mm}$, and 27.5 $\mathrm{mm}$. The length and diameter of the duct where the flow expands are also varied during the analysis. The role played by four micro jets of $1 \mathrm{~mm}$ diameter as an orifice to regulate the base pressure. The results as the percentage increase in base pressure are plotted for different level expansion and area ratio. For higher $N P R=7$, the control significantly increases the base pressure without disturbing the wall pressure distribution. $L / D=3$ and 4 seems to be optimum in resulting in a maximum increase in base pressure. For lower area ratio the minimum duct length required is $L / D=3$, whereas for the highest area-ratio this limit is $L / D=$ 4.
\end{abstract}

Keywords-Active control, microjets, Mach number, expanded flows, area ratio.

\section{INTRODUCTION}

The flow separation phenomena in aerodynamic vehicles like rockets, missiles, projectiles, etc. cause the recirculation region to be formed, which results in low pressure. Generally, the pressure in this recirculation region is considerable of reduced strength than the pressure of the free stream atmosphere. The low pressure at the base results in pressure difference causing base drag which can be up to $2 / 3^{\text {rd }}$ of the total drag during their transonic speed [1]-[3]. In an internal combustion engine, the exhaust port has a similar flow condition where the jet of hot exhaust gases flows out through the exhaust value. The flow expansion is inward rather than outward in case of flow around the base of a missile/rocket in flight or blunt edged projectile, can be considered as another application of suddenly expanded flows [2]-[5].

Rathakrishnan et al. [3] analyzed the suddenly expanded subsonic flow field using the cavities as a passive control mechanism. From their study, it was concluded that the cavities effect on the primary flow field is well noticeable for bigger ducts and the aspect ratio of cavity also has a profound effect on the enlarged duct flow field and base pressure. With a change in aspect ratio from 2 to 3 , it was seen that the decrease in base pressure was obtained whereas with a change in aspect ratio from 3 to 4, caused an increase in base pressure. Asadullah et al. [6] analyzed wall pressure distribution for low supersonic Mach number, i.e., at 1.3.

Revised Manuscript Received on July 10, 2019.

Fharukh Ahmed G. M. Research scholar Department of Mechanical Engineering, Bearys Institute of Technology, Mangalore, Karnataka India.

Sher Afghan Khan Department of Mechanical Engineering Bearys Institute of Technology Mangalore, Karnataka India (sakhan06@gmail.com)
The results showed that the expansion and compression waves reduced drastically at $\mathrm{L} / \mathrm{D}=3$ due to variation in back pressure. NPR of 2.77 and 4.16 was used in another experimental investigation for base pressure reduction analysis using active control for an area ratio of 2.56. The $\mathrm{L} / \mathrm{D}$

8 and 10 revealed a completely different base pressure variation compared to $\mathrm{L} / \mathrm{D}$ ratios of higher values. Negligible increase in wall pressure for under expanded flows was obtained, and for the case of with and without control, the effectiveness remained the same [7].

Some of the literature work pertinent to suddenly expanded flows are reviewed as follows. Korst [8] studied the problem of base pressure problem in transonic as well as supersonic flow where the oncoming flow at the base was sonic and also supersonic after the wake. Depending upon the interaction among the adjacent free stream and the dissipative shear flow considering the mass in the wake, Korst devised a model (physical). Anderson and Williams [9] studied the sudden expansion of air by analyzing noise produced and base pressure in a cylindrical duct. The base pressure obtained was minimum due to the attached flow depending upon the duct to area ratio of the nozzle. BarHaim and Weihs investigated the control of the boundary layer by reducing drag in fully submerged bodies. By the suction from the boundary layer, the pressure can be increased from the axisymmetric bodies leading to control the separation and hence delaying the transition.

Baig et al. [10] performed experimental research using the control to reduce base pressure in sudden expansion flows with the axi-symmetric passage. Microjets at four different locations were used to control the base pressure. Mach numbers of $1.87,2.2$ and 2.58 were employed for the experimental investigation. The area ratio was fixed at 2.56 , and the ratio of length to diameter was varied from 1 to 10 . Nozzle pressure ratio (NPR) of the operating nozzles were changed from 3 to 11 . As high as a $65 \%$ increase in base pressure was obtained during their analysis, and it was found that the flow field was not disturbed in the enlarged duct in view of the microjets as a control mechanism.

Ashfaq et al. [11] carried out a series of experiment considering sonic Mach numbers to control the base pressure by providing four microjets. Area ratios of 2.56, $3.24,4.84$, and 6.25 , and L/D ratio of 1 to 10 was operated for the experimental analysis. The area ratio of 6.25 and NPR of 1.5, 2.0, and 3.0 was applied which lead to effective control of base pressure [12]. Another study is reported by

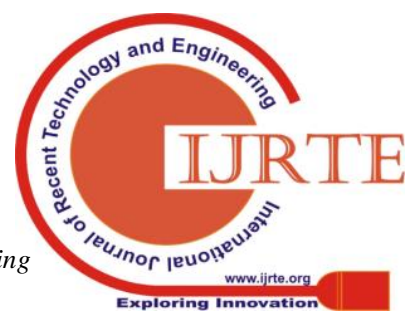


them for under expanded flow for subsonic and sonic flows with nearly the same configuration [13]. For Mach number 1.25 and nozzle diameter ratio of 1.6 experiments were performed for under-expanded and correctly expanded cases by Khan et

al. [14], [11], [15], [24], [16]-[23]. Surprisingly, the flow field became oscillatory for a particular combination of NPR and L/D ratio. They observed in the case of both controls and without control. Several other relevant research works carried out using active control include [21], [22], [25]-[32]. With this motivation, this article reports the change in base pressure in a sudden expanded converging nozzle flow at sonic Mach number, with duct diameters $16 \mathrm{~mm}, 22.5 \mathrm{~mm}$, and $27.5 \mathrm{~mm}$. The use of active control in the regulation of the base pressure is studied thoroughly, and hence an understanding of the role of micro jets is explored in this work.

\section{EXPERIMENTAL PROCEDURE}

Fig. 1 shows the essential features of sudden expansion flow filed is illustrated showing the reattachment point, expansion waves, and recirculation zone. The same concept is used to perform the experimental investigation with the application of four micro jets at the base as shown in Fig. 2. The experimental facility available at High-Speed Aerodynamics Laboratory (HSAL), IIT, Kanpur, is used for the experimentation. The experimental setup is shown in Figure 2. The side view shown at the right side of Fig. 2 shows the presence of eight holes along the circular position outer to the nozzle exit. The holes marked with ' $c$ ' are the microjets placed suitably for blowing, and holes ' $\mathrm{m}$ ' marked in the Figure are to measure the base pressure $\left(P_{b}\right)$. By blowing air, active control is accomplished through the holes ' $c$ ' consuming the pressure from a tube connected through the blowing chamber as shown in Fig. 2. The blowing chamber uses the pressure from the settling chamber whose NPR is the same.

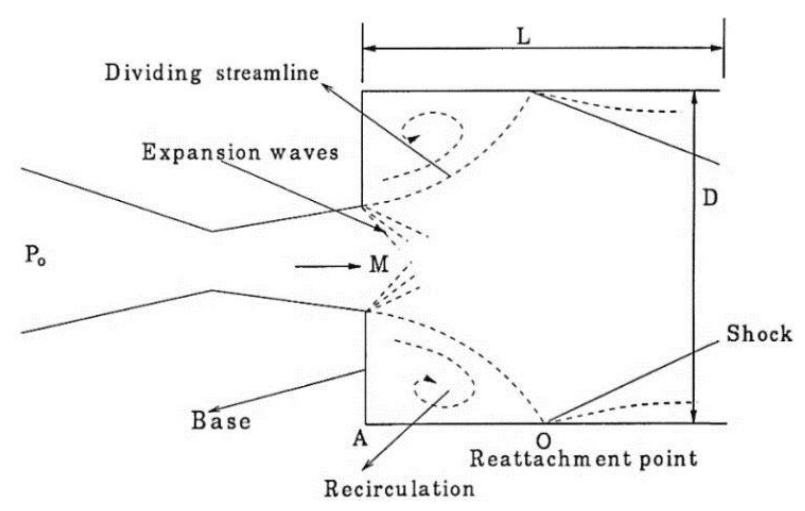

Fig. 1. The sudden expansion flow field

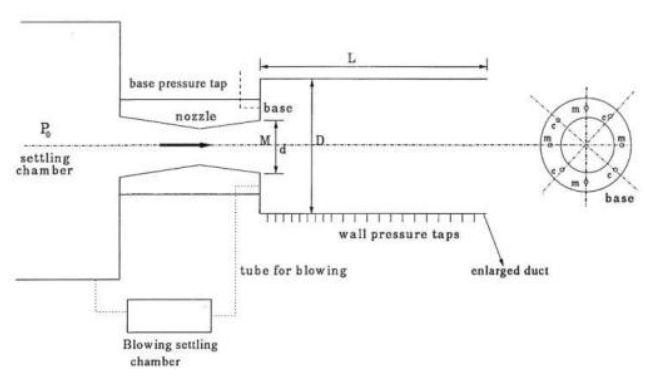

\section{Fig. 2. Experimental setup for active control}

The static pressure in the duct was measured to assess the impact of control on the nature of the flow field in the duct. For this, the pressure taps were used on the wall to record the wall pressure. At a distance of $8 \mathrm{~mm}$ each, holes are made which are nine in number, and the remaining holes are prepared at a distance of $10 \mathrm{~mm}$. The length to diameter ratio (L/D) used in this study is varied from 10 to 1 , and the readings for each ratio is conducted. The experiment is repeated for Mach numbers like 1.7, 2.3, and 2.7. However, in this article, we are discussing the results at sonic Mach number alone. In literature usually, L/D ratio employed is 3 to 5 for without control. With control, this ratio can be varied from 10 to 1 . For each value of each number, L/D ratio, with and without control the NPR is varied from 1 to 10 in a step of 1 each, and the readings are noted every single time. PSI System 2000 is used as a pressure transducer to record the change in base pressure variation. The pressure range is $0-300$ psi of the transducer employed, and it has 16 channels. The sampling rate of the pressure transducer is 250 samples per second, and then the reading is displayed on the monitor and recorded. The wall pressure was recorded using mercury manometer.

\section{RESULTS AND DISCUSSIONS}

The results of the percentage change in the base pressure in the converging nozzle at sonic Mach is analyzed for different length of duct and its diameters. The length of the duct varies in the form of L/D from 10 to 2 , and duct diameter varied was $16 \mathrm{~mm}, 22.5 \mathrm{~mm}$, and $27.5 \mathrm{~mm}$. The nozzle pressure ratio (NPR) is changed from 1 to 7 in steps of 1 . The NPR is the ratio of pressure in the chamber to atmospheric pressure, i.e. $\left(P_{o} / P_{a}\right)$. In Fig. 3 (a) and (b) the $\%$ change obtained for NPR 1 to 7 and L/D $=10$ to 5 and 4 to 1 are shown respectively. Starting from $L / D=10$ the change in base pressure is found to become negligible. The results show that the base pressure fluctuates at $\mathrm{L} / \mathrm{D}=10$ and remains unaltered at $L / D=1$. When the duct diameter is lower, the reattachment length is quite nearer to the nozzle exit area, and hence the recirculation zone is of the shorter area. In view of the considerable length of the duct (i.e., L/D $=10$ ) times the diameter of the duct. Hence the frictional effects play a crucial role in base pressure variation. Due to higher duct lengths, the active control role is marginal, and with a decrease in length, the control effectiveness is significant. From the results, it is found that after NPR 2 and $\mathrm{L} / \mathrm{D}=8$, the effectiveness has reversed and the base pressure has increased due to the decrease in adverse pressure gradient with an increase in NPR. L/D $=4$ and 3 have resulted in the maximum increase in the base pressure with the application of control at NPR greater than 2. For smaller duct lengths the control is of no use as the flow is attached with the duct.

Fig. 4 shows the base pressure changes for L/D from 10 to 2 for NPR increasing from 1 to 7 . Here the primary role is played by the duct diameter wherein the reattachment length increases and causes the increased dead zone and more chances of improvement in base pressure with the use of 
Fig. 4. \% Change in base pressure for duct diameter of $22.5 \mathrm{~mm}$

micro jets. For $\mathrm{L} / \mathrm{D}=10$ the control effect reverses at NPR $=2$, and for $\mathrm{L} / \mathrm{D}=8$ the control reverses at NPR $=3$. The same behavior is seen for other L/D ratios. The base pressure has increased by a maximum of $5 \%$ at the highest NPR. In Fig. 5 the base pressure increase is depicted for different NPR for duct diameter of $27.5 \mathrm{~mm}$. Here a significant issue is large area ratio resulting in increased reattachment length and hence very high base drag. The active control plays a prominent role now in increasing the base pressure. At $\mathrm{L} / \mathrm{D}=10$ the base pressure is same at all NPR. However, for $\mathrm{L} / \mathrm{D}=4$, the increase in base pressure is significant.

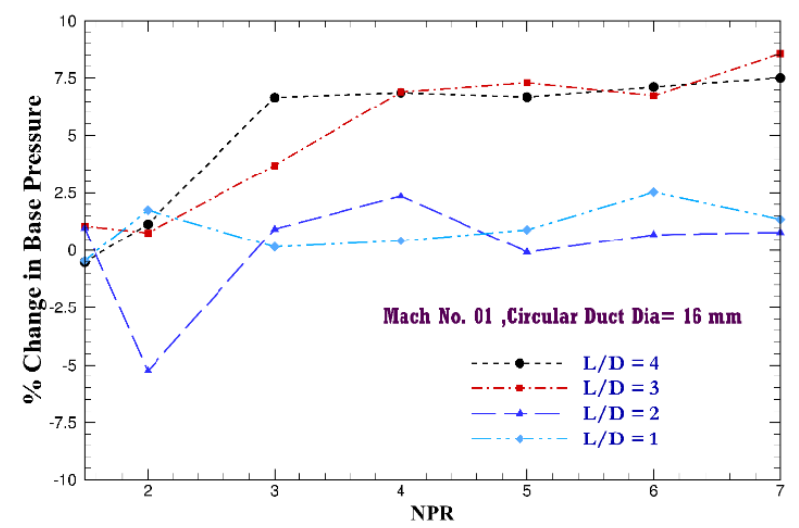

(a) $\mathrm{L} / \mathrm{D}=10$ to 5

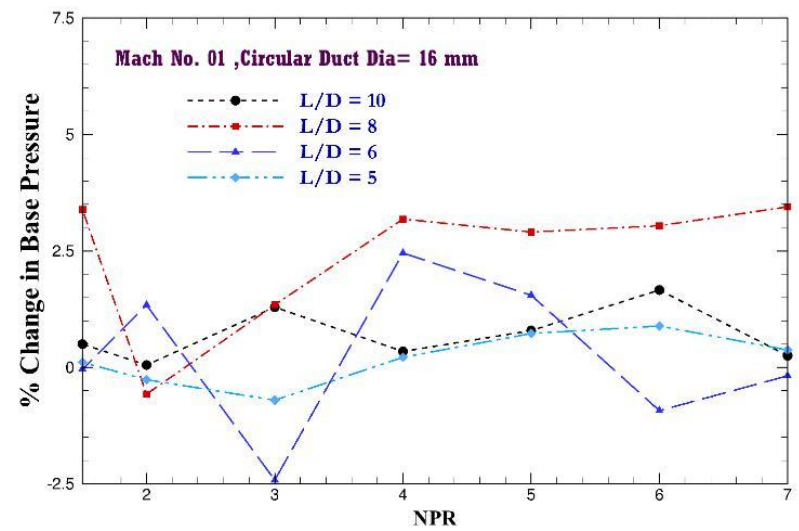

(a) $\mathrm{L} / \mathrm{D}=4$ to 1

Fig. 3. \% Change in base pressure for duct diameter of $16 \mathrm{~mm}$

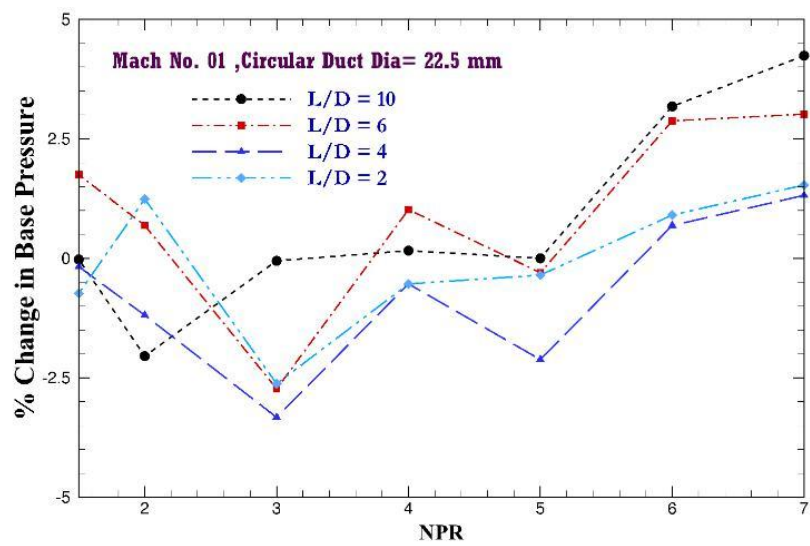

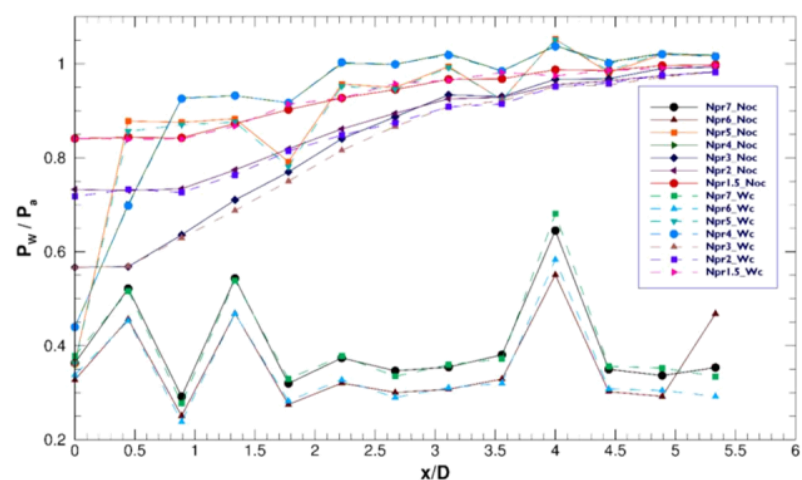

b) Duct diameter $22.5 \mathrm{~mm}$ and $\mathrm{L} / \mathrm{D}=6$

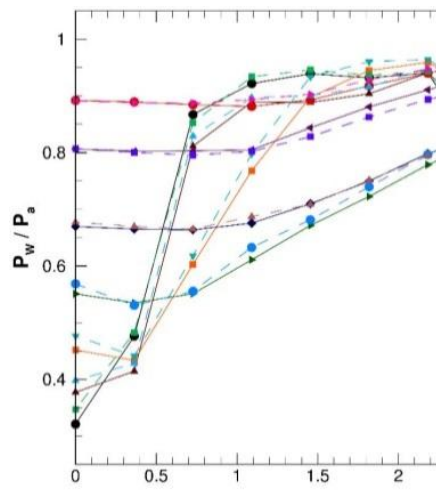

c)

Duct diameter 27.5 $\mathrm{mm}$ and $\mathrm{L} / \mathrm{D}=6$

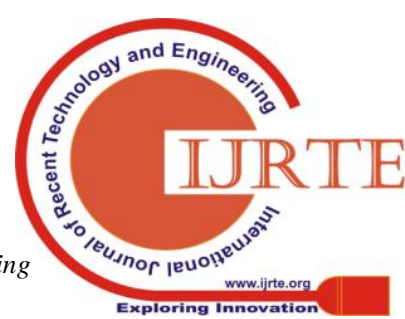




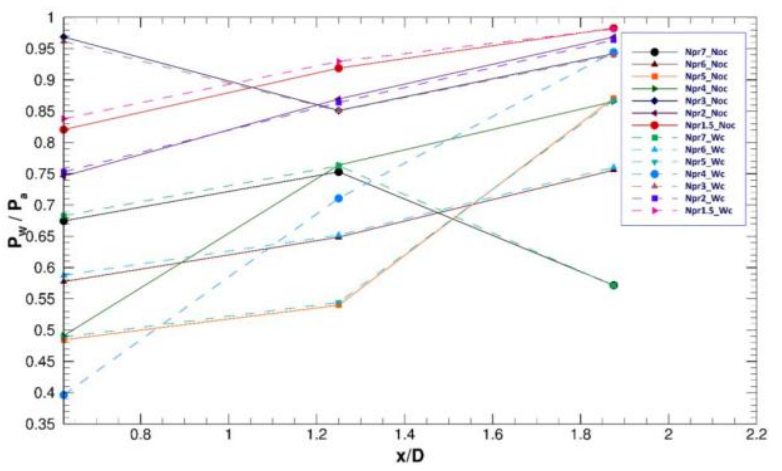

d) Duct diameter $16 \mathrm{~mm}$ and $\mathrm{L} / \mathrm{D}=2$

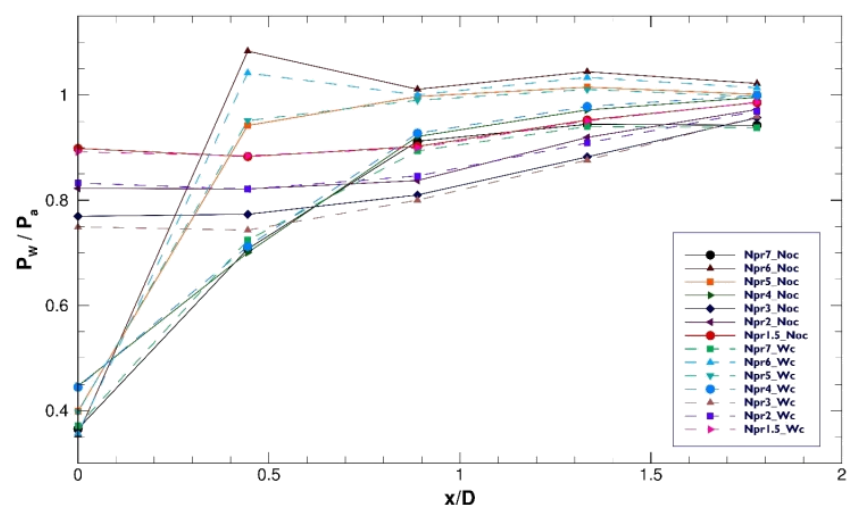

e) Duct diameter $22.5 \mathrm{~mm}$ and $\mathrm{L} / \mathrm{D}=2$

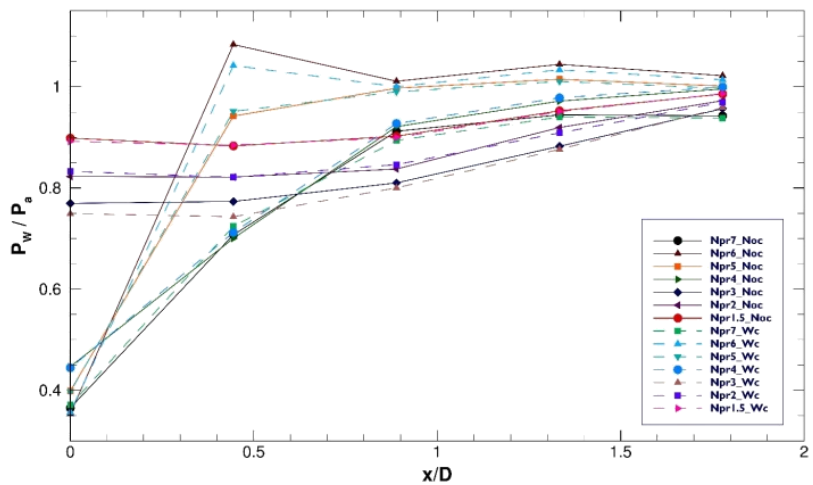

f) Duct diameter $27.5 \mathrm{~mm}$ and $\mathrm{L} / \mathrm{D}=2$

Fig. 6. Wall pressure for Mach 1.0, at $L / D=6$ and 2 and different duct diamters

With the increase in NPR, the decrease in base pressure is due to suction that causes the jets to perform better. An important influential aspect that is found is the optimum $\mathrm{L} / \mathrm{D}$ ratio at different duct diameters. This, in fact, is found to be at $\mathrm{L} / \mathrm{D}=3$ and 4 at all NPR and the duct diameters.

The distribution of static wall pressure for sonic Mach and $L / D=6$ and 2 with three different duct sizes are shown in the below Fig. 6 considering fixed L/D $=6$ for different NPR with and without control. The pressure field seems to be remained unchanged with control and without control. Hence the wall pressure does not get influenced adversely leading further to oscillations due to active control. Whenever we employ the control using either active or passive control in increasing the base pressure, the primary issue associated with control of base flow related to wall pressure in supplementing the oscillatory nature is wholly evaded. No issue is found to be in employing the control for sonic Mach flow field as obtained here. Hence active control plays a crucial role in increasing the base pressure without disturbing the flow field.

\section{CONCLUSION}

The improvement in base pressure with the active control at the sonic Mach number is investigated in detail.

The length to diameter ratio of the duct where the flow expands is varied from 10 to 1 . The diameters of the duct selected for the current analysis are $16 \mathrm{~mm}, 22.5 \mathrm{~mm}$, and $27.5 \mathrm{~mm}$. the NPR is also varied from 1 to 7 for different $\mathrm{L} / \mathrm{D}$ ratio and duct diameters. When the nozzles are under expanded the control becomes effective. The above results once again reiterate that the control is effective when there exists a favorable pressure gradient.

The wall pressure remained unaltered for all controlled flows. However, at large NPR due to the presence of the waves at the nozzle exit the fluctuation in the wall pressure is observed. The highest increase in base pressure reported is $6 \%$ in this article for the sonic flow and selected L/D ratio at the highest NPR.

\section{REFERENCES}

1. A. K. Rathakrishnan, E, Sreekanth, "Flows in pipes with sudden enlargement," in 14th International Symposium on Space Technology and Science, 1984, pp. 491-496.

2. P. R. Viswanath, "Passive Devices for Axisymmetric Base Drag Reduction at Transonic Speeds," J. Aircr., vol. 25, no. 3, pp. 258-262, 1988.

3. E. Rathakrishnan, O. V Ramanaraju, and K. Padmanaban, "Influence of Cavities on Suddenly Expanded Flow Field," Mech. Res. Commun., vol. 16, no. 3, pp. 139-146, 1989.

4. E. Rathakrishnan, "Effect of Ribs on Suddenly Expanded Flows," AIAA J., vol. 39, no. 7, pp. 1402-1404, 2001.

5. R. Srikanth and E. Rathakrishnan, "Flow through pipes with sudden enlargement," Mech. Res. Commun., vol. 18, no. 4, pp. 199-206, 1991.

6. M. Asadullah, M. Bashir, A. Janvekar, and S. A. Khan, "Active Control of Wall Pressure Flow Field at Low Supersonic Mach Numbers," IOSR J. Mech. Civ. Eng., pp. 90-98, 2016.

7. F. A. G. M, M. A. A. Baig, M. Bashir, and S. A. Khan, "Control of Ideally Expanded and under Expanded Nozzle Flow with Micro Jets," IOSR J. Mech. Civ. Eng., pp. 83-89, 2016.

8. H. Korst, "A theory of base pressure in transonic and supersonic flow," J. Appl. Mech., vol. 23, no. 4, pp. 593600, 1956.

9. J. S. Anderson and T. J. Williams, "Base pressure and noise produced by the abrupt expansion of air in a cylindrical duct," J. Mech. Eng. Sci., vol. 10, no. 3, pp. 262-268, 1968

10. S. A. Khan, M. Asadullah, F. A. G. M, A. Jalaluddeen, and A. Ahmed, Maughal Baig, "Passive Control of Base Drag in Comressible Subsonic Flow Using Multiple Cavity," Int. J. Mech. Prod., vol. 8, no. 4, pp. 39-44, 2018.

11. F. Ahmed and S. A. Khan, "Investigation of efficacy of low length-to-diameter ratio and nozzle pressure ratio on base pressure in an abruptly expanded flow," in MATEC Web of Conferences, 2018, vol. 01004, pp. 1-6.

12. S. Ashfaq and S. A. Khan, "Studies on Flow From Converging Nozzle and the Effect of Nozzle Pressure 
Ratio for Area Ratio of 6.25," Int. J. Eng. Sci. Adv. Technol., vol. 4, no. 1, pp. 49-60, 2014.

13. S. Ashfaq and S. A. Khan, "Combined Effect of Relief and Level of Expansion in a Suddenly Expanded Flow," IOSR J. Mech. Civ. Eng., vol. 12, no. 5, pp. 52-59, 2015.

14. S. A. Khan, M. Bashir, F. A. G. M, and M. A. Ullah, "An investigation of base flow control by wall pressure analysis in a sudden expansion nozzle," J. Sci. Res. Dev., vol. 3, no. 5, pp. 1-6, 2016.

15. S. A. Khan, M. Asadullah, F. A. G. M, A. Jalaluddeen, and A.

16. Ahmed, Maughal Baig, "Flow Control with Aerospike Behind Bluff Body," Int. J. Mech. Prod., vol. 8, no. 3, pp. 1001-1008, 2018.

17. F. A. G. M, A. A. Alrobaian, A. Aabid, and S. A. Khan, "Numerical Analysis of Convergent-Divergent Nozzle Using

18. Finite Element Method," Int. J. Mech. Prod. Eng. Res. Dev., vol. 8, no. 6, pp. 373-382, 2018.

19. F. A. G. M, M. A. A. Baig, M. Bashir, and S. A. Khan, "Control of Ideally Expanded and under Expanded Nozzle Flows with Micro Jets," IOSR J. Mech. Civ. Eng., pp. 83-89, 2016.

20. S. Manigandan and K. Vijayaraja, "Flow field and acoustic characteristics of elliptical jet," Aircr. Eng. Aerosp. Technol. An Int. J., vol. 90, no. 9, pp. 1364 1371, 2018.

21. K. A. Pathan, "CFD Analysis of Effect of Area Ratio on Suddenly Expanded Flows," in 2nd International Conference for Convergence in Technology, 2017, pp. 1192-1198.

22. S. A. Khan, M. Asadullah, F. A. G. M, A. Jalaluddeen, and A. Ahmed, Maughal Baig, "Flow Control with Aerospike Behind Bluff Body," Int. J. Mech. Prod., vol. 8, no. 3, pp. 1001-1008, 2018.

23. S. A. Khan, M. Asadullah, F. A. G. M, A. Jalaluddeen, and A. Ahmed, Maughal Baig, "Passive Control of Base Drag in Compressible Subsonic Flow Using Multiple Cavity," Int. J. Mech. Prod., vol. 8, no. 4, pp. 39-44, 2018.

24. S. A. Khan, M. Asadullah, and J. Sadhiq, "Passive Control of Base Drag Employing Dimple in Subsonic Suddenly Expanded Flow," Int. J. Mech. Mechatronics Eng., vol. 18, no. 3, pp. 6974, 2018.

25. S. A. Khan and E. Rathakrishnan, "Control of suddenly expanded flow," Aircr. Eng. Aerosp. Technol. An Int. J., vol. 78, no. 4, pp. 293-309, 2006.

26. S. A. Khan and E. Rathakrishnan, "Active Control of Suddenly Expanded Flows from Underexpanded Nozzles," Int. J. Turbo Jet Engines, vol. 21, pp. 233-254, 2004.

27. F. A. G. M, M. A. Ullah, and S. A. Khan, "Experimental Study of Suddenly Expanded Flows from Nozzle," ARPN J. Eng. Appl. Sci., vol. 11, no. 16, pp. 10041-10047, 2016.J. Quadros, S. A. Khan, and A J Antony, "Study of Effect of Flow

28. Parameters on Base Pressure in a Suddenly Expanded Duct at Supersonic Mach Number Regimes using CFD and Design of Experiments," J. Appl. Fluid Mech., vol. 11, no. 2, pp. 483-496, 2018.

29. S. A. Khan, Z. I. Chaudhary, and V. B. Shinde, "Base Pressure

30. Control by Supersonic Micro Jets in a Suddenly Expanded Nozzle," Int. J. Mech. Mechatronics Eng., vol. 18, no. 4, pp. 101-113, 2018.

31. F. Ahmed and S. A. Khan, "Investigation of the efficacy of low length-to-diameter ratio and nozzle pressure ratio on base pressure in an abruptly expanded flow," in MATEC Web of Conferences, 2018, vol. 01004, pp. 1-6.
32. M. Asadullah, S. A. Khan, W. Asrar, and E. Sulaeman, "Passive control of base pressure with the static cylinder at supersonic flow," Int. Conf. Aerosp. Mech. Eng., vol. 370, p. 012050, 2018.

33. M. Asadullah, S. A. Khan, W. Asrar, and E. Sulaeman, "Low-Cost

34. Base Drag Reduction Technique," Int. J. Mech. Eng. Robot. Res., vol. 7, no. 4, pp. 428-432, 2018.

35. A. A. Alrobaian, S. A. Khan, M. Asadullah, F. A. G. M, and Imtiyaz A, "A new approach to the low-cost opentyped subsonic compressible flow wind tunnel for academic purpose," Int. J. Mech. Prod., vol. 8, no. 6, pp. 383-394, 2018.

36. N. S. Vikramaditya, M. Viji, S. B. Verma, N. Ali, and D. $\mathrm{N}$.

37. Thakur, "Base Pressure Fluctuations on Typical Missile

38. Configuration in the presence of Base Cavity," $J$. Spacecr. Rockets, vol. 55, no. 2, pp. 335-345, 2018. 